\title{
A Cross-Sectional Analysis of Spin in Randomized Controlled Trials
}

\author{
Alexandra Woodbridge, BS, BA ${ }^{7}$, Ann Abraham, BS ${ }^{2}$, Rosa Ahn, BA ${ }^{3}$, Susan Saba, MPH', \\ Deborah Korenstein, $\mathrm{MD}^{5}$, Erin Madden, $\mathrm{MPH}^{2}$, and Salomeh Keyhani, $\mathrm{MD}, \mathrm{MPH}^{2,6}$
}

${ }^{1}$ Tulane University School of Medicine, New Orleans, LA, USA; ${ }^{2}$ San Francisco VA Medical Center, San Francisco, CA, USA; ${ }^{3}$ Oregon Health \& Science University, Portland, OR, USA; ${ }^{4}$ Stanford University School of Medicine, Palo Alto, CA, USA; ${ }^{5}$ Memorial Sloan Kettering Cancer Center, New York, NY, USA; ${ }^{6}$ University of California at San Francisco, San Francisco, CA, USA.

$\mathrm{J}$ Gen Intern Med 33(3):247-8

DOI: $10.1007 / \mathrm{s} 11606-017-4252-2$

(c) Society of General Internal Medicine (outside the USA) 2018

\section{INTRODUCTION}

Randomized controlled trials (RCTs) are the most reliable form of evidence for evaluating drug safety and efficacy. Because clinicians rely on RCTs to inform clinical practice, accurate representation of clinical trial results is important to patient health and safety. Spin, defined as reporting that distorts results or misleads the reader, ${ }^{1}$ threatens accurate evidence interpretation and application by clinicians. Given that many clinicians obtain information from the study abstract only, spin in the abstract is concerning. ${ }^{2}$ We examined the prevalence of spin among abstracts in a random sample of trials focused on the efficacy of drugs and examined the association of spin with study characteristics.

\section{METHODS}

We searched Medline for all English-language RCTs examining drug efficacy published in 2013. Our search identified 2851 potential studies. After screening titles and abstracts, 1101 potential studies remained. We randomly selected 646 of this sample, of which 190 studies were focused on drug efficacy and met inclusion criteria. For each study, we extracted information on outcome, funding source, financial ties to the manufacturer, and design characteristics (Table 1). The methods are described in full in a prior publication. ${ }^{3}$

\section{Identification of RCT Outcome}

Trained abstractors used the results section of each study to determine whether the study reported positive or negative primary efficacy outcome. For superiority studies, if the drug of interest was statistically superior to the control (e.g., $p$ value $<0.05$ ), the study outcome was defined as positive. For non-inferiority studies, if the drug of interest and the

Alexandra Woodbridge and Ann Abraham contributed equally to this work. Published online January 8, 2018 control had no significant difference, the study outcome was defined as positive. Study outcomes were assessed independently and in duplicate. Any disagreement on study outcome was resolved by discussion among the research team.

\section{Outcome Measure}

The main outcome variable considered was the presence or absence of spin in the abstract of the RCT. We considered spin present if the abstract outcome was positive or mixed and the study reported a negative primary efficacy outcome in the results section of the manuscript. ${ }^{1}$ Two clinician reviewers (SK, DK) evaluated all abstract conclusion sections, rating each conclusion as positive (in favor of study drug), negative (neutral or in favor of control), or mixed. A mixed rating meant that it was unclear in the abstract whether the study drug or the control was favored (i.e., if a subgroup analysis was emphasized over the primary outcome). The two clinicians remained blinded to the study outcome during this discussion.

\section{Analysis}

We report the prevalence of spin in a sample of RCTs. We examined the association between spin and study characteristics using a two-sided, 0.05 -level $\chi^{2}$ test of significance. Statistical analysis was performed using SAS version 9 statistical software (SAS Institute Inc., Cary, NC).

\section{RESULTS}

Of the 190 RCTs identified, 59 had a negative primary outcome in the results. These 59 studies were evaluated for the presence of spin. Among the 59 studies, clinician reviewers rated 8 abstracts as having a positive outcome and 17 as having a mixed outcome, for a total of 25 (42\%) abstracts with spin. Study characteristics were largely similar across studies with and without spin (Table 1). Overall, studies with spin had smaller samples (median: 201) than studies without spin (median: $352 ; p=0.03$ ). There was no relationship between any financial tie to the manufacturer and presence of spin in the abstract $(p=0.83)$. 
Table 1 Prevalence of Spin by Study Characteristics $(N=59)$

\begin{tabular}{|c|c|c|c|c|}
\hline & $\begin{array}{l}\text { All } \\
\text { studies } \\
(n=59) \\
\mathrm{N}\end{array}$ & $\begin{array}{l}\text { Spin } \\
\text { present } \\
(n=25) \\
\text { N }(\%)\end{array}$ & $\begin{array}{l}\begin{array}{l}\text { Spin } \\
\text { absent } \\
(n=34)\end{array} \\
\text { N }(\%)\end{array}$ & $\begin{array}{l}p \text { - } \\
\text { value }\end{array}$ \\
\hline Funding source & & & & 0.89 \\
\hline $\begin{array}{l}\text { No industry } \\
\text { involvement }\end{array}$ & 23 & $10(43)$ & $13(57)$ & \\
\hline $\begin{array}{l}\text { Financial ties of PI } \\
\text { present }\end{array}$ & & & & 0.08 \\
\hline Yes & 29 & $9(31)$ & $20(69)$ & \\
\hline No & 30 & $16(53)$ & $14(47)$ & \\
\hline \multicolumn{5}{|c|}{ Any relationship with manufacturer (funding and/or financial ties) } \\
\hline Yes & 41 & $17(42)$ & $24(58)$ & 0.83 \\
\hline No & 18 & $8(44)$ & $10(56)$ & \\
\hline Sample size & & & & $0.01 *$ \\
\hline Q1 (24-109) & 15 & $10(67)$ & $5(33)$ & \\
\hline Q2 (110-270) & 15 & $5(33)$ & $10(67)$ & \\
\hline Q3 $(271-410)$ & 14 & $8(57)$ & $6(43)$ & \\
\hline Q4 (411-13,229) & 15 & $2(13)$ & $13(87)$ & \\
\hline $\begin{array}{l}\text { First author affiliation } \\
\text { by continent }\end{array}$ & & & & 0.17 \\
\hline Europe & 22 & $10(45)$ & $12(55)$ & \\
\hline North America & 27 & $8(30)$ & $19(70)$ & \\
\hline Asia & 7 & $5(71)$ & $2(29)$ & \\
\hline Other & 3 & $2(67)$ & $1(33)$ & \\
\hline $\begin{array}{l}\text { First author affiliation } \\
\text { by country }\end{array}$ & & & & 0.35 \\
\hline USA & 23 & $8(35)$ & $15(65)$ & \\
\hline Other & 36 & $17(47)$ & $19(53)$ & \\
\hline Specialty & & & & 0.63 \\
\hline Cardiology & 9 & $3(33)$ & $6(67)$ & \\
\hline Oncology & 7 & $4(57)$ & $3(43)$ & \\
\hline Other & 43 & $18(42)$ & $25(58)$ & \\
\hline Trial registration & & & & 0.69 \\
\hline Yes & 53 & $22(42)$ & $31(58)$ & \\
\hline No & 6 & $3(50)$ & $3(50)$ & \\
\hline RCT type & & & & 0.93 \\
\hline Phase 2 & 21 & $9(43)$ & $12(57)$ & \\
\hline Phase 3 & 26 & $10(38)$ & $16(62)$ & \\
\hline Phase 4 & 4 & $2(50)$ & $2(50)$ & \\
\hline Other & 8 & $4(50)$ & $4(50)$ & \\
\hline Type of analysis & & & & 0.24 \\
\hline Superiority & 58 & $24(41)$ & $34(59)$ & \\
\hline Non-inferiority & 1 & $1(100)$ & $0(0)$ & \\
\hline Comparator & & & & 0.59 \\
\hline Placebo & 49 & $20(41)$ & $29(59)$ & \\
\hline Active & 10 & $5(50)$ & $5(50)$ & \\
\hline Outcome measure & & & & 0.20 \\
\hline Clinical & 45 & $17(38)$ & $28(62)$ & \\
\hline Surrogate & 14 & $8(57)$ & $6(43)$ & \\
\hline Blinding & & & & 0.40 \\
\hline Double-blinded & 46 & $18(39)$ & $28(61)$ & \\
\hline Open-label & 12 & $6(50)$ & $6(50)$ & \\
\hline Single-blinded & 1 & $1(100)$ & $0(0)$ & \\
\hline
\end{tabular}

*Kruskal-Wallis p-value of 0.03 based on medians for studies with spin (201) vs. those without (352)

PI principal investigator

\section{DISCUSSION}

Nearly half of abstracts of RCTs focused on drug efficacy that report negative results contain spin. We did not find an association between spin and financial ties to industry, but our study may be underpowered to detect this association. Many clinicians do not read beyond the abstract, and many readers of the literature may not have the skill to critically analyze a trial themselves to combat spin or other bias in the report. ${ }^{4-6}$ Given the widespread reliance on the abstract, the peer review process needs to be improved to reduce spin in abstracts. A simple prompt asking reviewers to comment on the presentation of the results of the study with a specific question about spin may help focus reviewer attention on this issue. Editors can also review for spin in the editorial decision process. These simple steps that allow more scrutiny of the abstract and provide feedback to authors may reduce, if not eliminate, spin in the literature.

Corresponding Author: Salomeh Keyhani, MD, MPH; San Francisco VA Medical Center, San Francisco, CA, USA (e-mail: Salomeh. keyhani@ucsf.edu).

Funding This project was not directly supported by any research funds. Dr. Keyhani is funded by grants from the NIH (grants RO1 HL116522-01A1, RO1 HL114563-O1A1) and VA HSR\&D (1IP1HX001994). Dr. Korenstein's work on this paper was supported by a Cancer Center Support Grant from the National Cancer Institute to Memorial Sloan Kettering Cancer Center (award number P3O CA008748).

\section{Compliance with Ethical Standards:}

Prior Presentations: SGIM meeting April 21, 2017.

Conflict of Interest: All authors declare that they have no conflict of interest.

Ethical approval: Not needed.

Data sharing: Data set available from corresponding author on request.

Transparency: The manuscript's guarantor (SK) affirms that this manuscript is an honest, accurate, and transparent account of the study being reported; that no important aspects of the study have been omitted; and that any discrepancies from the study as planned have been explained.

This is an open-access article distributed under the terms of the Creative Commons Attribution Non-commercial License, which permits use, distribution, and reproduction in any medium, provided the original work is properly cited, the use is noncommercial and is otherwise in compliance with the license. See: http://creativecommons.org/ licenses/by-nc/2.0/ and http://creativecommons.org/licenses/bync/2.0/legalcode.

\section{REFERENCES}

1. Boutron I, Dutton S, Ravaud P, Altman DG. Reporting and Interpretation of Randomized Controlled Trials With Statistically Nonsignificant Results for Primary Outcomes. JAMA. 2010; 303(20): 2058-64. doi: https://doi. org/10.1001/jama.2010.651

2. Saint S, Christakis DA, Saha S, et al. Journal reading habits of internists. J Gen Intern Med. 2000;15(12):881-4. doi:https://doi.org/10. 1046/j.1525-1497.2000.00202.x

3. Ahn R, Woodbridge A, Abraham A, et al. Financial ties of principal investigators and randomized controlled trial outcomes: cross sectional study. BMJ. 2017;356:i6770. doi: https://doi.org/10.1136/bmj.i6770.

4. Caverly TJ, Matlock DD, Prochazka AV, Lucas BP, Hayward RA. Interpreting Clinical Trial Outcomes for Optimal Patient Care: A Survey of Clinicians and Trainees. J Grad Med Educ. 2016;8(1):57-62. doi: https://doi.org/10.4300/JGME-D-15-00137.1.

5. Johnson TV, Abbasi A, Schoenberg ED, et al. Numeracy among trainees: are we preparing physicians for evidence-based medicine? J Surg Educ. 2014;71(2):211-5. doi: https://doi.org/10.1016/j.jsurg.2013.07.013.

6. Korenstein D. Blinding Them With Science? Evidence-Based Medicine as a Barrier to Health Care Value. J Grad Med Educ 2016;8(1):106-8. doi: https://doi.org/10.4300/JGME-D-15-00570.1. 